\title{
Review of the background and application of triolein-containing semipermeable membrane devices in aquatic environmental study
}

\author{
Yibing Lu ${ }^{\text {a }}$, Zijian Wang ${ }^{\mathrm{a}, *}$, James Huckins ${ }^{\mathrm{b}}$ \\ ${ }^{a}$ State Key Laboratory of Environmental Aquatic Chemistry, Research Center for Eco-Environmental Sciences, Beijing 100085, \\ China \\ ${ }^{\mathrm{b}}$ Columbia Environmental Research Center, USGS, Columbia, MO, USA
}

Received 5 March 2002; accepted 15 April 2002

\begin{abstract}
This paper briefly reviews research on passive in situ samplers for aquatic environments but focuses on the development and application of the triolein-containing semipermeable membrane device in aquatic environmental monitoring. Special attention is paid to the calibration of the devices, quality control issues, and its potential uses in environmental assessments of aquatic contaminants. Also, the suitability of the technique for incorporation with selected bioassays is examined. (C) 2002 Elsevier Science B.V. All rights reserved.
\end{abstract}

Keywords: Review; Triolein-semipermeable membrane device; Calibration; QA/QC; Applications

\section{Introduction}

Chemicals listed by the US EPA as priority pollutants contribute little to broad environmental indices such as BOD, COD or TOC. Never the less, these contaminants can pose a major threat to ecosystem and human health. For example, many substances that cause cancer belong to persistent organic contaminants (POPs). In 1999, the China EPA designated 40-organic contaminants from US EPA's list of 2347 toxic chemicals as priority pollutants for water quality standards.

\footnotetext{
* Corresponding author. Tel.: + 86-10-62849140; fax: + 8610-6292-3563.

E-mail address: wangzj@mail.rcees.ac.cn (Z. Wang).
}

Nearly all-environmental samples require some type of preparation before analysis. Conventional solid phase extraction (SPE), such as XAD resin sorption, and liquid-liquid extraction are among the oldest and most frequently used sample preparation methods. However, use of these methods for monitoring ultra trace to trace-level (e.g. pg to $\mathrm{ng} / \mathrm{L}$ ) organic contaminants in water, may be problematic. More specifically, difficulties or limitations associated with the methods are often encountered when collecting and extracting large volumes of water needed for trace contaminant analysis. These include sampling and handling induced changes in some water quality parameters, and loss of analytes due to filtration, 
volatilization and sorption. Also, analysis of excised water reflects residue composition only at the moment of sampling and may fail to detect episodic contamination events (Huckins et al., 1990a, 1993). Therefore, the recent availability of SPE cartridges has facilitated the analysis of many environmental samples, but the method is generally more suitable for the analysis of samples with moderate (e.g. $\mu \mathrm{g} / \mathrm{L}$ ) to trace levels of target contaminants.

Because of the aforementioned difficulties in analyzing trace-level contaminants, the levels of POPs in water are often inferred from their equilibrium concentrations in the tissue of aquatic organisms. Weaknesses in this approach include possible metabolism and depuration of accumulated chemicals, prejudices in absorption, site-tosite variations in organism stress, and limited viability (Prest et al., 1995b), which affect equilibrium concentrations. Estimates of POP concentrations in water can also be made by measuring their concentrations in benthic sediments from rivers, lakes or seashores and then using equilibrium distribution coefficients (i.e. $K_{\mathrm{oc}} \mathrm{s}$ ) to derive levels of dissolved phase analytes (Gale et al., 1997). This approach is limited by the assumption of equilibrium between sediments and the water column, and the potential effects of organic carbon quality differences among sediments that are not accounted for in current equilibrium partition models.

Increasingly, the development of effective, economic and selective passive sampling techniques is becoming a widespread goal of environmental scientist. In particular there is a need for techniques, which fulfill the demands of monitoring trace or ultra-trace bioavailable organic contaminants in water and at the same time bridge the gaps between environmental analytical chemistry and ecotoxicology approaches. Among various passive sampling approaches for organic contaminants, the solid phase micro-extraction (SPME) fibers and semipermeable membrane devices (SPMDs) appear to show the most promise. SPME fibers are widely accepted as analytical tools for measuring semi-volatile contaminants (Pawliszyn, 1997), are very convenient to use, but are generally limited by small sample size/capacity.
Several passive samplers have been proposed based on the diffusion of hydrophobic substances from the water to membrane bags filled with lipophilic phases. Some of the early designs included dialysis bags made of regenerated cellulose tubing and polyethylene membrane bags filled with hexane (Sodergren, 1987, 1990; Johnson, 1991; Hasset et al., 1989). At about the same time, Zabik (1988) and Huckins (1988) evaluated polypropylene, polyvinyl chlorides, polyacetate, and silicone membranes for use in passive samplers. In other studies (Byrne and Aylott, 1980), vinyl chlorides, polyvinylidene fluoride, polytetrafluoro ethylene, acrylic copolymer and nylon membrane bags were used as semipermeable membranes for passive samplers. Also, polyethylene membranes were filled with XAD-4 and $\mathrm{C}_{18}$, or common organic solvents such as 2,2,4-trimethylpentane, octanol, and hexane for environmental sampling (Zabik et al., 1992). Pekol and Cox (1995) described a system in which micellar Brij35 and Brij58 were used in combination with a cellulose ester dialysis membrane. The micellar media compared well with organic solvents as receivers for fugacity based membrane preconcentrators of hydrophobic compounds. In a comparative study (Macrae and Hall, 1998), triolein-containing semipermeable membrane device (triolein-SPMD), Tenax TA, and polyethylene tube dialysis (PTD) of sediment were used to estimate the available fraction of polycyclic aromatic hydrocarbons (PAHs) in marine sediment slurries. The results of this study suggested that PTD is useful for assessing chemical exposure from to soils or sediments, while triolein-SPMD and Tenax TA are useful for estimation of the fraction of chemicals in sediments that would likely be biodegradable in reasonable length of time.

Recently a polar organic chemical integrative sampler (POCIS), consisting of a hydrophilic polyethersulfone membrane containing an admixture of a hyper-cross linked polystyrene-divinylbenzene SPE resin and S-X3 Biobeads coated with fine particles of dispersed Ambersorb ${ }^{\circledR} 1500$, was designed (Alvarez et al., 2000). The polyethersulfone membrane was selected because of all the membranes studied; it exhibited the greatest up- 
take of hydrophilic analytes and had the greatest membrane durability. Using POCIS samplers, linear uptake of polar analytes (e.g. atrazine) was observed through 28 days, and biofouling was minimal.

Besides SPME fibers, the most popular passive sampling configuration for aquatic environments is the triolein-containing SPMD developed by Huckins (1988) and Huckins et al. (1990a). Fig. 1 illustrates the principle of the triolein-SPMD. The following sections summarize the theory, practice, and applications of SPMDs as passive in situ samplers of aquatic environments.

\section{Design and basis of triolein-SPMDs}

\subsection{Generic configuration}

All triolein-SPMDs contain a thin film of lipid sealed within an additive free layflat polyethylene (LDPE) tube. LDPE employed in triolein-SPMDs is referred to as nonporous, although random

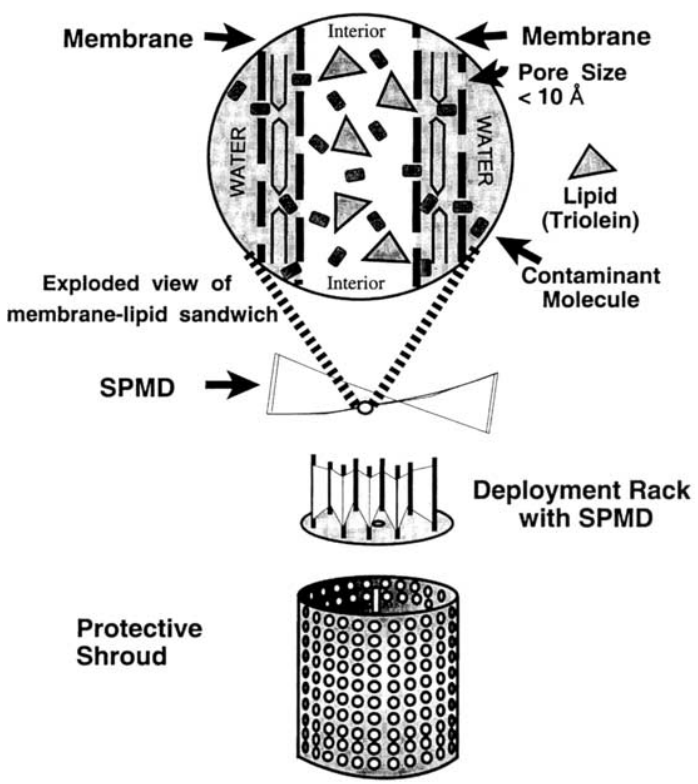

Fig. 1. Illustration of the principle of nonporous membrane size-exclusion phenomenon, which mediates the containment of triolein-SPMD lipid and allows the diffusive exchange of smaller analyte molecules. Also, a partial illustration of deployment apparatus is shown as well. Courtesy of Carl Crazio and Randal Clark, USGS, Colombia, MO, USA. thermal motions of the polymer chains form transient cavities with maximum diameters of approximately $10 \AA$ (Huckins et al., 1990a). Because the cross-sectional diameters of most environmental contaminant molecules are nearly as large as LDPE cavities, only dissolved (i.e. readily bioavailable) organic contaminants can diffuse into the membrane and be concentrated in the membrane and triolein. The neutral-triglyceride triolein was selected for use in SPMDs for the following reasons: (1) it is a significant constituent of fish lipids; (2) Chiou (1985) has shown a good correlation between equilibrium triolein-water partition coefficients $\left(K_{\mathrm{tw}} \mathrm{s}\right)$ and widely available equilibrium octanolwater partition coefficients $\left(K_{\mathrm{ow}} \mathrm{s}\right)$; (3) the high molecular weight of triolein (i.e. $>800 \mathrm{Da}$ ) greatly reduces LDPE membrane permeability even during organic solvent dialysis; and (4) triolein is commercially available in high purity forms (Huckins et al., 1990a, 1993, 1996).

Triolein-SPMDs were designed to mimic the bioconcentration of organic contaminants in fatty tissues of organisms, using a much more reproducible sampling matrix. Among the many potential environmental variables, uptake rates are only affected by temperature, flow velocity-turbulence, and biofouling. SPMDs can be used for in situ monitoring contaminants, estimating respiratory exposure, concentrating trace organic contaminants for assessing their toxicity, and the LDPE tubing can be used for analytical separations (Huckins et al., 1990a,b; Meadows et al., 1993; Strandberg, 1998; Bergqvist et al., 1998a). Huckins et al. (1990a, 1993, 1996, 1999, 2000) have delineated important considerations in the design, application, performance, and data comparability of SPMDs.

\subsection{Models for estimation of ambient concentration}

Procedures for the estimation of ambient water concentrations of contaminants from their concentrations in triolein-SPMDs are different from those used in active sampling strategies. In general, sample size and thus concentration factors are not predetermined for SPMD exposures, as is common in active sampling strategies. There are many mathematic models developed to estimate ambient 
analyte concentration based on first-order exchange kinetics and equilibrium partitioning concepts (Booij et al., 1998; Huckins et al., 1993; Huckins et al., in press). Perhaps, the most simple and common approaches used are the equilibrium (Eq. (1)), linear uptake kinetics (Eq. (2)), and exponential accumulation (Eq. (3)) models given by Huckins et al. (1993).

$\frac{C_{\mathrm{t}}}{C_{\mathrm{w}}}=K_{\mathrm{tw}}$

$\frac{C_{\mathrm{t}}}{C_{\mathrm{w}}}=\frac{R_{\mathrm{s}} t}{V t}$

$\frac{C_{\mathrm{t}}}{C_{\mathrm{w}}}=K_{\mathrm{tw}}\left(1-\mathrm{e}^{-k_{\mathrm{u}} t}\right)$

Eq. (1) describes the equilibrium partitioning of a pollutant between the triolein and water phases, where $C_{\mathrm{t}}$ is the concentration of the contaminant in the lipid (does not include membrane contribution), $C_{\mathrm{w}}$ is the water concentration, and $K_{\mathrm{tw}}$ was defined earlier. Eq. (2) is based on the assumption that $C_{t}$ is linearly related to the sampling time, where $R_{\mathrm{s}}$ is the chemical-specific SPMD (triolein alone) sampling rate, expressed as the volume of water cleared of chemical per unit time $(t)$, and $V_{\mathrm{t}}$ is the volume of the lipid in the device. The $R_{\mathrm{s}}$ values for chemicals of interest are independent of analyte concentration and are obtained through laboratory exposures under controlled conditions. Eq. (3) is based on the assumption that $C_{\mathrm{t}}$ is exponentially related to the exposure time, where $k_{\mathrm{u}}$ is defined as the overall uptake rate constant and is mathematically identical to the loss rate constant $\left(k_{\mathrm{e}}\right)$. Eq. (3) integrates all three phases of SPMD uptake (i.e. linear, curvilinear and equilibrium). Because triolein-SPMDs have a large capacity for hydrophobic contaminants, most lipophilic analytes will not achieve equilibrium within sampling periods of $<28 \mathrm{~d}$.

A simple relationship between $\log K_{\mathrm{tw}}$ and $\log K_{\text {ow }}$ can be applied (Chiou, 1985) for the derivation of $K_{\mathrm{tw}}$, used in Eq. (1) and Eq. (3).

$\log K_{\mathrm{tw}}=\log K_{\mathrm{ow}}+0.105$

where $K_{\text {ow }}$ was defined earlier and values are available for most of the priority contaminants.

Application of Eqs. (1)-(3) is also based on the assumption that the chemicals accumulated by triolein-SPMDs are only in the triolein phase. However, the membrane is a functional constituent in the sampling process rather than simply a container for the triolein (Huckins et al., 1990a; Petty et al., 1994; Gale, 1998; Booij et al., 1998). Studies have indicated that the polyethylene membrane used in triolein-SPMD is a significant reservoir for hydrophobic residues and has a membrane/solute partitioning coefficients only a little less than the inner triolein reservoir $\left(K_{\mathrm{pw}} \approx\right.$ $0.1-0.5 K_{\mathrm{tw}}$, Gale, 1998). For example, a typical sampler has a total mass of about $4.5 \mathrm{~g}$, which contains $0.91 \mathrm{~g}(1 \mathrm{ml})$ of triolein and represents a polyethylene to triolein ratio of about 4:1 (Huckins et al., 1996). This finding implies that about 33$71 \%$ of the total accumulated chemicals are in triolein phase at steady state.

If the lipid and membrane are analyzed together (e.g. organic solvent dialysis of intact SPMDs), a simple alternative to modeling lipid accumulation alone is to substitute $V_{\mathrm{SPMD}}$ for $V_{\mathrm{t}}$ and $C_{\mathrm{SPMD}}$ for $C_{\mathrm{t}}$ in Eq. (2) to obtain the empirical sampling rates for the whole device (Huckins et al., 1999):

$\frac{C_{\mathrm{SPMD}}}{C_{\mathrm{w}}}=\frac{R_{\mathrm{s}}^{\prime} t}{V_{\mathrm{SPMD}}}$

where $R_{\mathrm{s}}^{\prime}$ is the sampling rate for the whole device (i.e. polyethylene plus triolein), $C_{\mathrm{SPMD}}$ is the concentration in the whole device, and $V_{\mathrm{SPMD}}$ is the volume of the whole sampler.

A three-compartment (3C) differential equation model has been developed and used to describe the kinetics of the accumulation processes (Gale, 1998). Based on the 3C model, it was suggested that the accumulation of a chemical in a trioleinSPMD may be controlled by either: (1) polymer film diffusion for large molecules with low polymer diffusivity, where steady-state solute concentrations in polyethylene and water are reached before they attained in polyethylene and triolein; (2) aqueous film diffusion for highly polymer-diffusive molecules, where the ratio of the solute concentrations in triolein and polyethylene reaches steady state before the whole device approaches steady state with the water; (3) a combination of aqueous and polymer film diffusion where solute concentrations in polyethylene and 
triolein reach a relatively constant ratio, but not necessarily the final steady-state value (i.e. equilibrium concentrations among the three compartments). By modeling potential variations in exposure conditions and the triolein-SPMD physical parameters, the overall accumulation by the whole devise is predicted to remain under aqueous film control for high $K_{\text {ow }}$ compounds. However, for very large molecules, accumulation in the triolein may be subject to polymer film control.

In the literature, most of the $R_{\mathrm{s}}$ (or $R_{\mathrm{s}}^{\prime}$ ) values were obtained under controlled laboratory conditions (Huckins et al., 1993, 1999; Huckins et al., in press, Rantalainen et al., 2000). When triolein-SPMDs are used in natural environments periphyton often attach to the exterior of the membrane and contribute to the total impedance to chemical uptake. Ellis et al. (1995) reported extensive biofouling of triolein-SPMD membranes during an exposure on the upper Mississippi River. Periphyton growth varies with environmental conditions under which the device was deployed, and it is difficult to correct for its influence. Huckins et al. (1993, 1996, 1997a) and Huckins et al. (1999) and Huckins et al. (2000) have proposed the use of permeability/performance reference compounds (PRCs; i.e. selected compounds spiked into SPMD triolein prior to deployment), which provide information that can be used to derive in situ trioleinSPMD sampling rates. Thus, laboratory-sampling rates $\left(R_{\mathrm{s}} \mathrm{s}\right)$ of triolein-SPMDs can be adjusted to reflect specific field sampling conditions, such as biofouling, by introducing a coefficient $F_{\mathrm{i}}$, which is defined as one minus the fractional reduction in sampling rate due to biofouling (Petty et al., 2000):

$R_{\mathrm{sc}}=R_{\mathrm{s}} F_{\mathrm{i}}$

where $R_{\mathrm{sc}}$ is the corrected sampling rate for a chemical and is obviously a conditional constant for a specific set of exposure conditions. Currently, the PRC approach has been extended to the effects of temperature and flow velocity-turbulence of the medium sampled (Huckins et al., in press), which permits the derivation of an exposure adjustment factor (EAF). The EAF accounts for the effects of all three environmental variables (i.e. flow-turbulence, temperature and biofouling) affecting triolein-SPMD sampling rates. Correct use of the
PRC approach should enable investigators to predict water concentrations with estimation errors of less than twofold (Huckins et al., in press).

\subsection{Quality control}

The level of quality control related to trioleinSPMD applications varies with project goals and the analytical procedures used. A typical analytical scheme for analyzing organic contaminants in triolein-SPMDs includes sample preparation, extraction, enrichment/purification, fractionation, and quantitative or qualitative analysis. For example, analysis of PAHs in triolein-SPMDs generally includes dialytic recovery of the PAHs from the intact device, cleanup the dialysate using size exclusion and adsorption chromatography, then analysis by gas chromatography (GC) with photoionization or mass spectrometric detection (Lebo et al., 1992, Orazio et al., 1995). More specifically, triolein-SPMDs are dialyzed in hexane to recover the analytes, followed by high performance size exclusion chromatography and potassium silicate enrichment procedures (Petty et al., 2000). The precision of this process, including sampling and analysis, is typically better than 20\% RSD (Petty et al., 2000). In the case of triolein-SPMDs, used to preconcentrate water samples for bioassays or biomarker tests, cleanup is typically less rigorous than that described above. However, some potential lipid impurities may still interfere with the assay. This issue is subsequently discussed in more detail.

Devita and Crunkilton (1998) applied trioleinSPMDs to monitor PAHs in an urban stream. Relative percent differences (RPDs) were calculated to estimate precision in triolein-SPMD replicates and RPDs were found within 13.9-56.0\% $(n=14)$.Variations in replicates encompassed triolein-SPMD preparation, deployment, exposure, retrieval and analysis, and the average percent recoveries were $52-82 \%(n=7)$. The method detection limits (MDLs) were assessed by spiking each of 10 triolein-SPMDs with $0.200 \mathrm{mg}$ PAHs per $g$ triolein. After a 14-day exposure period, the MDLs for the PAHs studied corresponded to

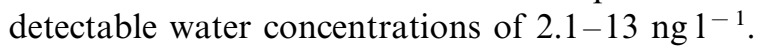
These values were as much as 2000 times lower than MDLs derived from standard approach of 
solvent extraction of water samples. In general, the quality control criteria used for GC-mass spectrometric identification of target chemicals in triolein-SPMDs is the same as other sampling strategies (Strandberg, 1998). Clearly, when interlaboratory results are compared, there is a need for the standardization of triolein-SPMDs to ensure comparability of results.

\section{Environmental monitoring and research applications}

Since the beginning of the 1990s, triolein-SPMDs have received wide recognition, especially in the United States, as effective tools for environmental research and analysis. They have been successfully used for monitoring chemicals in aquatic environments (Huckins et al., 1990a Huckins et al., 1997b; Petty et al., 1995, 1998; Ellis et al., 1995; Lebo et al., 1992, 1995; Bennett et al., 1996; Moring and Rose, 1997; Bergqvist et al., 1998a; Axelman et al., 1999; Zimmerman et al., 2000), and in air (Ockenden et al., 1998; Lohmann et al., 2001). Triolein-SPMDs have also been used for screening and preliminary identification of emission sources in wastewater systems and groundwater (Stuer-Lauridsen and Kjolholt, 2000; Granmo et al., 2000; Gustavson and Harkin, 2000), and appear to simulate the bioconcentration of dissolved chemicals by aquatic organisms (Huckins et al., 1996; Prest et al., 1992; Wood, 1994; Devita and Crunkilton, 1994; Herve et al., 1995; Peven et al., 1996; Hofelt and Shea, 1997). The procedure for dialytic recovery of analytes can be used separately to remove lipids and other interferences from environmental sample extracts (Huckins et al., 1990b; Meadows et al., 1993, 1996; Strandberg, 1998; Bergqvist et al., 1998b).

In general, triolein-SPMDs can be used for a wide range of organic contaminants. However, chemicals that are predominantly ionic at environmental $\mathrm{pHs}$ are not accumulated in trioleinSPMDs. In addition, chemicals with $\log K_{\mathrm{ow}} \mathrm{s}<2.0$ are too polar or their fugacity from non-polar organic phases is too high to be sufficiently concentrated in triolein-SPMDs.

\subsection{Comparisons to biomonitoring organisms}

Triolein-SPMDs have been proposed as a mimetic (i.e. to mimic complex biological processes in simple media) supplement or replacement for biomonitoring organisms used in organic contaminant assessments (Herve et al., 1995; Prest et al., 1995a). Regardless of the issue of the appropriate application of triolein-SPMDs to biomonitoring programs, these authors found triolein-SPMDs to be very useful tools for assessing the presence of bioavailable organic contaminants.

The capacity of an organism to accumulate non-metabolized organic contaminant residues is mainly controlled by the lipophilicity (i.e. $K_{\mathrm{ow}}$ ) of the compound and the lipid content of the organism. Usually, a correlation between bioconcentration factor (BCF) and the device (triolein-SPMD) concentration factor (DCF) is assumed, when triolein-SPMDs are substituted for organism in extreme environments. However, Huckins et al. (in press) has pointed out that organism uptake rate constants vary widely for the same chemical and unlike triolein-SPMDs their tissues levels may not be proportional to environmental concentrations. Thus, it is unlikely that correlation between BCFs and DCFs will always be found (Huckins et al., in press). A good correlation was shown between the $\log K_{\text {ow }}$ and $\log$ BAF (bioaccumulation factor) in mussels and between the $\log K_{\text {ow }}$ and $\log$ DCF (Sabaliunas et al., 1998). These findings are based on a continuous-flow laboratory exposure of triolein-SPMDs and lake mussels (Anodonta piscinalis) to four pesticides (Sabaliunas et al., 1998). The compositions and ratios of different pesticides in triolein-SPMDs and in mussels were also similar, which indicate that triolein-SPMDs serve as good surrogates for aquatic organisms with respect to the discriminatory uptake of these hydrophobic chemicals (Sabaliunas et al., 1998). When goldfish (Crassius auratus) and triolein-SPMD were simultaneously exposed to nine relatively hydrophilic chlorophenols in a laboratory continuous flow experiment, steady state concentrations were achieved after $12 \mathrm{~h}$ in triolein-SPMDs and in fish, and the partition coefficients $\left(\log K_{\mathrm{tw}}\right.$, $\log \mathrm{BCF}$, and $\log K_{\mathrm{ow}}$ ) were closely cor- 
related each other (Wang et al., 1998). Similar results were obtained for nine weakly hydrophobic nitroaromatics (Wang et al., 1999a).

In field studies, the relationship between $\log$ DCFs and $\log$ BCFs often becomes more difficult to establish, mostly because of problems related to the measurement of free concentrations of contaminants in complex mixtures and the much longer times to equilibrium for SPMDs. For chemicals with high $K_{\text {ow }}$ s, i.e. $\log K_{\text {ow }}$ s $>6.0$, attainment of equilibrium in standard triolein-SPMDs may require more than a year (Gale, 1998). However, similar concentrations of chemicals have been reported in side-by-side field exposures of triolein-SPMDs and biomonitoring organisms (Prest et al., 1998; Gale et al., 1997). Hofelt and Shea (1997) suggested that the correlation between SPMDs and monitoring organisms was improved when using a device with a smaller volume of triolein, a thinner LDPE membrane and a larger membrane surface area $(25 \mu \mathrm{m}$ thick and $900 \mathrm{~cm}^{2}$ in area). The correlation coefficients $\left(R^{2}\right)$ for triolein-SPMDs and caged mussels (Mytilus edulis) ranged from $0.57-0.85$ for individual pesticides $(n=16)$ and from $0.81-0.96$ for individual congeners of polychlorinated biphenyl (PCB, $n=$ 20). However, based on the work of Booij et al. (1998) and Gale (1998), membrane thickness should have little to do with time to equilibrium of contaminants with $\log K_{\mathrm{ow}}$ s greater than about 5.0. Also, when benthic organisms (i.e. Lumbriculus variegates) and triolein-SPMDs were exposed simultaneously to sediment-bound chemicals, such as polychlorinated diphenylethers (PCDEs), BCFs and DCFs were reasonable close (Kukkonen et al., 1998).

The propensity of some organisms to rapidly biotransform certain anthropogenic chemicals, such as PAHs (Buhler and Williams, 1989), through activation of the mixed function oxidases (MFOs), severely limits any correlation between concentrations in tissue concentrations and exposure concentrations. Because no biotransformation or metabolism of chemicals occurs in triolein-SPMDs (assuming photolysis is prevented), they can be used to determine the relative roles of uptake from water (the bioconcentration process) and by difference, the dietary route (the BAF reflects both routes of uptake).
Application of triolein-SPMDs with PRCs to monitoring programs could improve the inter-laboratory comparability of residue concentration data for many contaminants (Huckins et al., in press). Because a variety of SPMD designs have been employed for environmental assessments without PRCs or appropriate calibration data, the comparability of these data will be questionable. Even if PRCs are used, shortcomings will exist in the extrapolation of triolein-SPMD data to some organisms, such as the inability to directly predict (models are required for these estimates) contaminant transfer up through the food web, i.e. SPMD levels do not reflect the potential for biomagnification. Clearly, triolein-SPMDs can be applied to discriminate bioconcentration from bioaccumulation in field studies. In summary, even though several laboratory and field tests have shown that triolein-SPMD and test organism tissue concentrations are remarkably similar across a wide range of chemical hydrophobicities, it is unreasonable to expect SPMDs to closely mimic the accumulation of all organic contaminants by all biomonitoring test species (Huckins et al., 2000).

\subsection{Use in chemical monitoring}

Since their inception, triolein-SPMDs have been largely intended for passively monitoring chemical concentrations in different environmental media. There are several advantages in using SPMDs for monitoring priority organic pollutants, which include the following: (1) the non-mechanical or passive operation; (2) the ability to sample large sample volumes (i.e. volume of water or air extracted) and (3) the generally reduced effort required for triolein-SPMD deployment and analytical cleanup when compared to transplanted organisms.

The following studies are specific examples of triolein-SPMD use for environmental contaminant monitoring. Prior to and after an extensive Midwest (USA) flood of 1993, triolein-SPMDs were employed to detect the presence of bioavailable organochlorine pesticides (OCs), PCBs, and PAHs in the water of the main stem of the lower Missouri River, and its tributaries (Petty et al., 1995, 1998). Contaminant residues found at post- 
flood sites were nearly all at higher concentrations than those found in the earlier pre-flood sampling. Dieldrin was found to range from a low of 110 ng sample ${ }^{-1}$ in the Gasconade River to a high of $2000 \mathrm{ng}$ sample ${ }^{-1}$ at Glasgow, while in the preflood sampling, dieldrin ranged from a low of 64 ng sample ${ }^{-1}$ at Sioux City to a high of 800 ng sample ${ }^{-1}$ at Glasgow (Petty et al., 1998).

In a study on the temporal distribution patterns of different contaminants in flood-plume water along the Swedish Coast, DDTs, PCBs, and dieldrin showed elevated levels during the first and second sampling period (Bergqvist et al., 1998b). Then, a more stable, but lower contaminant level followed. Surprisingly, chlordanes and hexachlorocyclohexanes (HCHs) showed a more complex pattern with elevated levels at the beginning, followed by a temporary decrease and then a second rise in concentrations. Chlorobenzenes showed no measurable shift in concentrations during the total sampling period (Bergqvist et al., 1998b).

Ultra-trace organic contaminants can be detected by using triolein-SPMDs. Following dialysis, cleanup, and fractionation, concentrations of polychlorinated dibenzo- $p$-dioxins (PCDDs) and polychlorinated dibenzofurans (PCDFs) as low as $30 \mathrm{fg}^{-1}$, were detected (Lebo et al., 1995) in aqueous exposures using a composite sample of four triolein-SPMDs (17 g, includes mass of membrane and triolein). Also, the average TCDD equivalents obtained from residue quantitation by GC/MS was generally similar to that measured by a H4IIE bioassay (Lebo et al., 1995).

Rantalainen et al. (1998) compared the levels and the congener profiles of PCDDs, PCDFs and non- $o, o^{\prime}$-PCBs sampled by triolein-SPMDs in the water column and in the sediments of the lower Fraser River (Canada). Triolein-SPMD concentrations were compared to concentrations in resident benthic-feeding fish. SPMD derived concentration estimates of the water column were compared to measured values as determined by an active Infiltrex ${ }^{\circledR}$ sampler equipped with SPE columns. The results suggested that triolein-SPMDs are the most suitable for sampling water for contaminants such as $\mathrm{PCDD} / \mathrm{Fs}$ and non- $o, o^{\prime}-$ $\mathrm{PCBs}$, which are present at ultra-trace levels in the environments of interest (Rantalainen et al., 1998). In another case, extracts from SPE of water samplers, triolein-SPMDs, fish and sediment were compared for their efficacy as monitors of prior pollutants in the Yanghe River, China. Triolein-SPMD appeared to be the most efficient approach (Wang et al., 1999b). The trioleinSPMD approach also has an advantage of being useable in extreme environmental and climatic conditions. For example, it was successfully deployed at McMurdo station in Antarctica in both the water column and sediments (Crockett, 1994).

Triolein-SPMDs have been shown to concentrate several other types of compounds of environmental concern, such as organometallics (Folsvik et al., 2000) and volatile olefinic and aromatic hydrocarbons. The latter hydrocarbons include monoterpenes, which are emitted from bark wounds as part of a tree defense mechanism and during wood processing (Strandberg, 1998). More specifically, triolein-SPMDs can be used to concentrate monoterpenes to adequate levels, so that the post identification and analysis is easier to perform.

Both Prest et al. (1998) have suggested that triolein-SPMDs are unsuitable for determining rapid or short-term temporal variability, since they are designed to integratively sample (i.e. they provide time weighted average [TWA] concentrations) over periods on the order of days or weeks not hours. Also, Gustafson suggested that triolein-SPMDs might be unsuitable for monitoring gas exchange of chemicals across the air-water interface, because flux is dependent upon instantaneous concentration gradients. In such circumstance, Prest et al. (1998) suggested that the simultaneous air and water sampling with SPEs and triolein-SPMDs is likely to be a powerful tool for assessing the net flux of chemicals between these compartments. His argument was based the observation that thermodynamic relationships for air-water transport are formulated in terms of dissolved and vapor phase concentrations and the triolein-SPMD membrane inherently provides a level of discrimination against particle bound chemicals (Prest et al., 1995a,b; Ockenden et al., 1998, Booij et al., 1998). When triolein-SPMDs 
are applied to soil ecosystem, they provide a simple and efficient in situ method for the concentration of pollutants in compost, as well as lipophilic vapors above the soil surface (Strandberg, 1998).

In principle, triolein-SPMDs were designed to sequester free concentrations (i.e. dissolved and vapor phases) of chemicals in waters. However, the fraction of free concentrations of very hydrophobic contaminants in natural waters and air may be small when compared to the total concentrations. For example, dissolved PCB congener concentrations in water samples from a contaminated spring were assessed with triolein-SPMDs and total water-borne PCB concentrations were determined separately with a conventional solvent extraction (i.e. liquid/liquid partitioning) approach (Meadows et al., 1998). Concentrations of dissolved hydrophobic chemicals in water $\left(C_{\mathrm{wd}}\right)$ were related to the TOC content of the water by the following equation (Meadows et al., 1998):

$$
C_{\mathrm{wd}}=\frac{m_{\mathrm{a}(\mathrm{tol})}}{m_{\mathrm{w}}+M_{\mathrm{oc}} K_{\mathrm{oc}}}
$$

where $m_{\mathrm{a}(\mathrm{tol})}$ is the total mass of analyte, $m_{\mathrm{w}}$ is the mass of water, $K_{\mathrm{oc}}$ is the compound's organic carbon sorption coefficient, and $M_{\mathrm{oc}}$ is the mass of organic carbon in the water. The results of this exercise show that the total organic carbon content of the water is critical in determining the amount of high $K_{\text {ow }}$ compounds accumulated by triolein-SPMDs or biota, because of its impact on the fractional amount of the dissolved, or readily bioavailable residues in water. For example, assuming that $K_{\mathrm{oc}} \approx K_{\mathrm{ow}}$, dissolved concentration of PCBs with $\log K_{\text {ow }}$ greater than 7.0 are reduced by more than $80 \%$ when correcting for $0.5 \mathrm{mgl}^{-1}$ TOC. However, aquatic organisms that ingest carbon rich particulates or prey organisms with very hydrophobic chemicals may accumulate a significant fraction of the residues by assimilation across the gut.

\subsection{Preconcentration of samples for bioassays}

There appears to be considerable need for rapid, easy to use, effective, and low-cost integrative methods that allow not only the direct moni- toring of the fate and concentrations of trace-contaminant mixtures in the environment, but also an assessment of the potential hazards these chemicals pose to aquatic organisms and human health. Extracts of triolein-SPMDs can be examined with standard bioassays (Huckins et al., 1996; Sabaliunas and Sodergren, 1997). Often, risk assessment of organic contaminants in aquatic environments is based on the measurement of individual compound levels and comparison of each chemical's concentration to existing toxicity data. However, all chemicals exert their effects as components of complex environmental mixtures that are influenced by a number of factors. Clearly, it is the effects of the complex mixtures that must be considered in a comprehensive environmental risk assessment. When trioleinSPMDs are used as surrogates for or in conjunction with biomonitoring organisms, the sequestered contaminants are available for assessment with a wide array of biomarker and bioassay tests. For example, concentrations of the dialysates of triolein-SPMDs have been assayed with standard bioindicator screening tests, such as Microtox and Mutatox (Huckins et al., 1996), or the ethoxy resorufin-o-deethylase assay (Niewolny et al., 1995). Consequently, this triolein-SPMDbioassay linkage provides a potential means of determining the relative biological significance of contaminants mixtures accumulated at study sites.

There have been numerous trials using trioleinSPMDs for ecotoxicology applications. Enriched extracts from triolein-SPMDs exposed to bleach Kraft mill effluents (Huckins et al., 1996) and surface water contaminated by trace levels of PCDDs and PCDFs (Huckins et al., 1996; Lebo et al., 1995) were found to induce cytochrome P450 activity in fish and rat cell lines. Purified dialysates from triolein-SPMDs, which were exposed to pesticides in a laboratory continuousflow system or deployed in polluted water in Lithuania, were highly toxic to the luminescent bacteria Vibrio fischeri (Sabaliunas and Sodergren, 1997). It is noteworthy that these bioassays were performed with only a small portion of dialysate. However, sample clean-up procedures to remove oleic (an impurity is some triolein) may be required prior to toxicity testing for the estima- 
tion of the true toxic potential of accumulated pollutants (Sabaliunas et al., 1999).

In freshwater microcosm studies that simulated a crude oil spill, triolein-SPMDs were used to concentrate the oil related pollutants in air, water columns and sediments. By using triolein-SPMDs the time-dependent changes in the acute toxicity (as assayed by Microtox ${ }^{\circledR}$ ) and the genotoxicity (as assayed by Mutatox ${ }^{\circledR}$ ) were successfully monitored (Johnson, 1995). The combination of the use of triolein-SPMDs for the preconcentration of certain trace contaminants (e.g. PAHs) and the subsequent assay of enriched dialysates by bioindicator tests appears to be an useful approach for screening the relative toxicity of bioavailable organic contaminants (Johnson et al., 2000). Triolein-SPMDs were deployed in the Athabasca River area to sequester any hydrophobic toxic compounds from different point sources along the river. The SPMD-extracts were assayed for MFO induction in a fish cell line (Parrott et al., 1995). Discharges from three pulp mills were found to have pollutants that strongly induced MFO activity in the cell line, when compared to the background river water.

Koistinen et al. (1998), used liquid-liquid extraction, SPE, and triolein-SPMDs to extract pollutants from the effluents and sludge of primary and secondary clarifiers of activated sludge treatment plants at a Finnish bleached-kraft pulp and paper mill, and then assessed the resulting extracts with two Hepa-1 mouse hepatoma cells bioassays. SPMDs were found to be particularly useful in accumulating non-polar inducers of MFO from the pulp mill effluents. Petty et al. (1998) exposed SPMDs to Missouri River water at several sites following the great flood of 1993 (Midwest USA). Enriched extracts of triolein-SPMD laboratory processing controls injected into rainbow trout (Oncorgynchus Myriss) showed no evidence of vitellogenin production (a bioindicator of the presence of estrogenic chemicals), whereas injection of extracts from SPMDs exposed at the Napoleon site on the river showed enhanced estrogenic activity in the trout. The authors suggest that these data indicate that long-term exposure of fish and wildlife to this type of contaminant mixture, may result in reproductive perturbations.

\subsection{Overview of attributes and drawbacks}

From the investigations summarized in this work, it is clear that triolein-SPMDs have considerable potential as monitors of environmental pollutants. However, all sampling or monitoring methods have strengths and weaknesses and triolein-SPMDs are no exception. Table 1 compares the attributes and drawbacks of triolein-SPMDs and two other common environmental monitoring approaches.

\section{Conclusions}

The most common applications of triolein-SPMDs appear to be the determination of the presence, source, and TWA concentrations of hydrophobic organic contaminants in aquatic environments and in the atmosphere. Also, trioleinSPMDs are often used as surrogates for, or additions to biomonitoring studies to improve estimates of exposure to waterborne organic contaminant mixtures, and in some cases, to predict tissue concentrations of specific contaminants in the tissues of organisms of concern (Petty et al., 1998). To reduce the magnitude of the error associated with a triolein-SPMD derived water concentration estimate, PRCs must be used to correct for site-specific environmental factors such as variations in temperature, membrane biofouling, and the flow-turbulence regime (Booij et al., 1998; Booij and Drooge, 2001 Huckins et al., 1997b, 1999, 2000; Huckins et al., in press). Standardization of the design of the triolein-SPMDs (e.g. membrane thickness and triolein to membrane mass ratios) is also needed to improve the comparability of triolein-SPMD data (Huckins et al., 1999).

The use of triolein-SPMDs as a tool for the assessment of the ecological consequences of chemical pollution is promising, particularly when the effects of long-term exposure to ultra-trace hydrophobic contaminants are a primary concern. Triolein-SPMDs can be used as a mimetic surrogate or as a compliment to biomonitoring organisms (Huckins et al., 2000) for the determination of bioavailable contaminants in aquatic environ- 


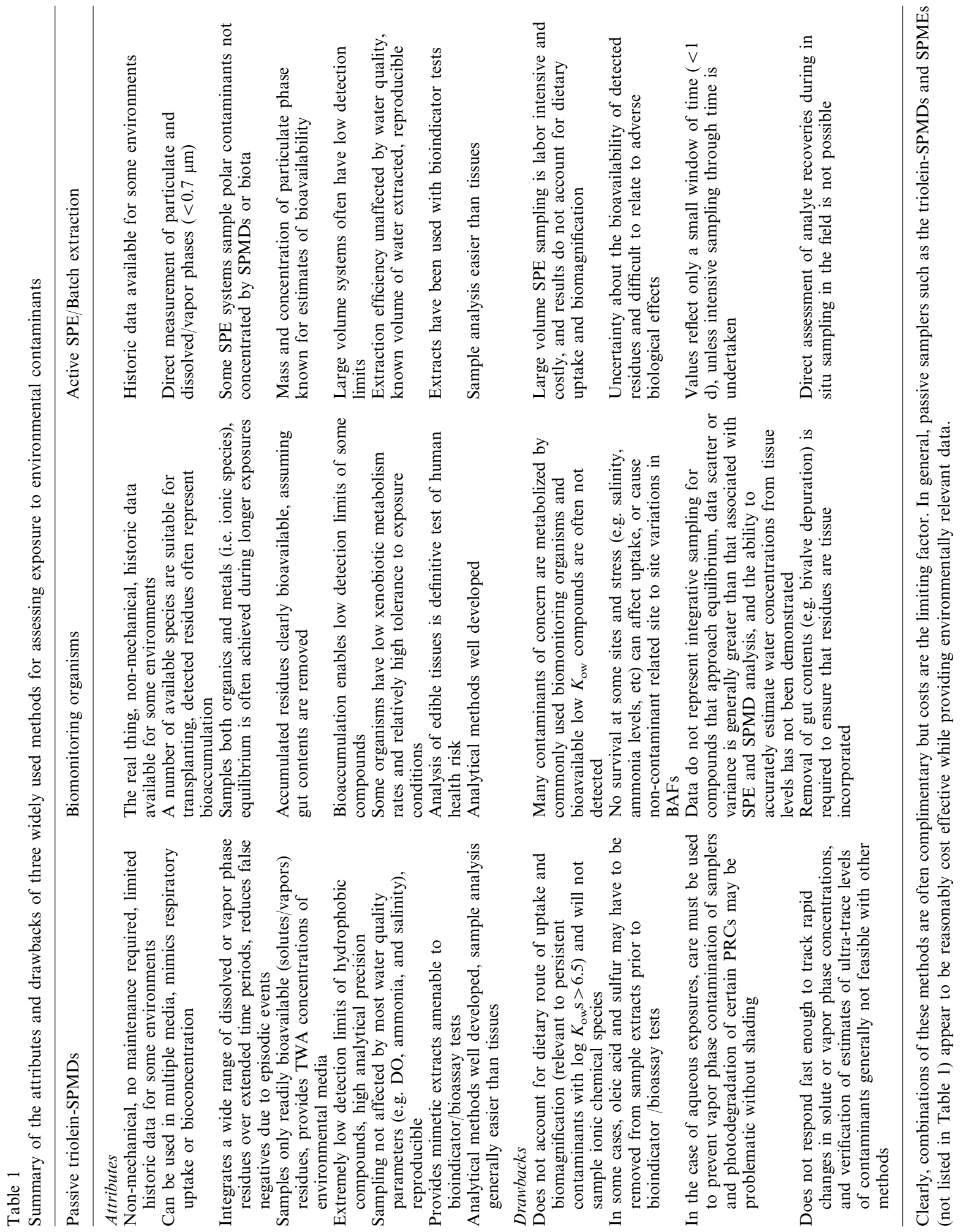


ments. The mimetic nature of triolein-SPMDs, suggest that bioassays of SPMD extracts will be more representative of feral organism responses than a combination of active sampling traditionally used followed by bioassay of sample extracts. Although more research work is needed to fully develop the aforementioned applications, considerable progress has been made.

\section{Acknowledgements}

This work is supported by China Natural Science Foundation (29977024) and by The Chinese Academy of Sciences (KZCX2-410, RCEES-KIP9901).

\section{References}

Alvarez, D.A., Huckins, J.N., Petty, J.D., Manahan, S.E., 2000. Progress towards the development of a passive, in situ, SPMD-like sampler for hydrophilic organic contaminants in aquatic environments. 20th Annual Meeting of the Society of Environmental Toxicology and Chemistry, 14-18th November, Philadelphia, PA, PWA096.

Axelman, J., Naes, K., Naf, C., Broman, D., 1999. Accumulation of polycyclic aromatic hydrocarbons in semipermeable membrane devices and caged mussels (Mytilus edulis) in relation to water column phase distribution. Environ. Toxicol. Chem. 18, 2454-2461.

Bennett, E.R., Metcalfe, T.L., Metcalfe, C.D., 1996. Semipermeable membrane devices (SPMDs) for monitoring organic contaminants in the Otonabee River, Ontario. Chemosphere 33, 363-375.

Bergqvist, P.-A., Srandberg, B., Ekelund, R., Rappe, C., Granmo, A., 1998a. Temporal monitoring of organochlorine compounds in seawater by semipermeable membranes following a flooding episode in Western Europe. Environ. Sci. Technol. 32, 3887-3892.

Bergqvist, P.-A., Strandberg, B., Rappe, C., 1998b. Lipid removal using semipermeable membranes (SPMDs) in PCDD and PCDF analysis of fatrich environmental samples. Chemosphere 38, 933-943.

Booij, K., Sleiderink, H.M., Smedes, F., 1998. Calibrating the uptake kinetics of semipermeable membrane devices using exposure standards. Environ. Toxicol. Chem. 17, 12361245.

Booij, K., Drooge, B.L.V., 2001. Polychlorinated biphenyls and hexachlorobenzene in atmosphere, sea-surface microlayer, and water measured with semi-permeable membrane devices (SPMDs). Chemosphere 44, 91-98.
Buhler, D.R., Williams, D.E., 1989. In: Varanasi, U. (Ed.), Metabolism of Polycyclic Aromatic Hydrocarbons in the Aquatic Environment. CRC press, Inc, Boca Raton, FL, USA, pp. 151-184.

Byrne, B.A., Aylott, R.I., 1980. Concentration for removing organic materials from aquatic systems. British Patent, No. 1566253.

Chiou, C.T., 1985. Partition coefficients of organic compounds in lipid-water systems and correlations with fish bioconcentration factors. Environ. Sci. Technol. 19, 5762.

Crockett, A.B., 1994. Initial experience in the deployment of lipid dosimeters in Antarctica. Second International Semipermeable Membrane Devices Workshop, US Department of the Interior, Columbia Environmental Research Center, Columbia, MO.

Devita, W.M., Crunkilton, R.L., 1994. Effectiveness of semipermeable membrane devices, fathead minnows, and rusty crayfish to monitor polynuclear aromatic hydrocarbons in an urban stream. Second international Semipermeable Membrane Devices Workshop, US Department of the Interior, Columbia Environmental Research Center, Columbia, MO.

Devita, W.M., Crunkilton, R.L., 1998. Quality control associated with use of semipermeable membrane devices. Environ. Toxicol. Risk Assess. 7, 237-245.

Ellis, G.S., Huckins, J.N., Rostad, C.E., Schmitt, C.J., Petty, J.D., MacCarthy, P., 1995. Evaluation of lipid-containing semipermeable membrane devices (SPMDs) and gas chromatography-negative chemical ionization-mass spectrometry for monitoring organochlorine contaminants in the upper Mississippi River. Environ. Toxicol. Chem. 14, 1875-1884.

Folsvik, N., Brevik, E.M., Berge, J.A. Monitoring of orgaotin compounds in seawater using semipermeable membrane devices (SPMDs) - tentative results. 2000. J. Environ. Monitoring 2, 281-284.

Gale, R.W., 1998. Three-compartment model for contaminant accumulation by semipermeable membrane devices. Environ. Sci. Technol. 32, 2292-2300.

Gale, R.W., Huckins, J.N., Petty, J.D., Peterman, P.H., Williams, L.L., 1997. Comparison of the uptake of dioxin-like compounds by caged channel catfish and semipermeable membrane devices in the Saginaw River, Michigan. Environ. Sci. Technol. 31, 178-187.

Granmo, A., Ekelund, R., Berggren, M., Brorstrom-Lunden, E., Berbgqvist, P., 2000. Temporal trend of organochlorine marine pollution indicated by concentrations in mussels, semipermeable membrane devices, and sediment. Environ. Sci. Technol. 34, 3323-3329.

Gustavson, K.E., Harkin, J.M., 2000. Comparison of sampling techniques and evalutation of semipermeable membrane devices (SPMDs) for monitoring polynuclear aromatic hydrocarbons (PAHs) in groundwater. Environ. Sci. Technol. 34, 4445-4451. 
Hasset, J., Force, M., Song, H., 1989. A passive in-situ extraction sampler for organic compounds in water: laboratory studies with PCBs. Extended abstracts of papers: 198th meeting of the American Chemical Society, CAS, Washington, D.C., 180.

Herve, S., Prest, H.F., Heinonen, P., Hyotylainen, T., Koistinen, J., Paasivirta, J., 1995. Lipid-filled semipermeable membrane devices and mussels as samplers of organochlorine compounds in lake water. Environ. Sci. Pollut. Res. 2, 24-30.

Hofelt, C.S., Shea, D., 1997. Accumulation of organochlorine pesticides and PCBs by semipermeable membrane devices and Mytilus edulis in New Bedford Harbor. Environ. Sci. Technol. 31, 154-159.

Huckins, J., Petty, J., Lebo, J., Orazio, C., 1997a. Comment on 'Accumulation of organochlorine pesticides and PCBs by semipermeable membrane devices and Mytilus edulis in New Bedford Harbor'. Environ. Sci. Technol. 31, $3732-$ 3733.

Huckins, J.N., 1988. Unpublished laboratory data. United states Geological Survey, Columbia Environmental Research Center, Columbia, MO, USA.

Huckins, J.N., Manuweera, G.K., Petty, J.D., Mackay, D., Lebo, J.A., 1993. Lipid-containing semipermeable membrane devices for monitoring organic contaminants in water. Environ. Sci. Technol. 27, 2489-2496.

Huckins, J.N., Petty, J.D., Gale, R.W., Orazio, C.E., Lebo, J.A., Clark, R.C., 2000. Effects of membrane thickness, salinity, and octanol-water partition coefficient $\left(K_{\text {ow }}\right)$ on lipid containing semipermeable membrane device (SPMD) exchange kinetics. 20th Annual Meeting of the Society of Environmental Toxicology and Chemistry, 14-18th November, Philadelphia, PA, PMP001.

Huckins, J.N., Petty, J.D., Lebo, J.A., Orazio, C.E., Prest, H.F., Tillitt, D.E., Ellis, G.S., Johnson, B.T., Manuweera, G.K., 1996. Semipermeable membrane devices (SPMDs) for the concentration and assessment of bioavailable organic contaminants in aquatic environments. In: Ostrander, G.K. (Ed.), Book Chapter in Techniques in Aquatic Toxicology. CRC-Lewis publishers, Boca Raton, FL, pp. 625-655.

Huckins, J.N., Petty, J.D., Orazio, C.E., Lebo, J.A., Clark, R.C., Gibson, V.A., Gala, W.R., Echols, C.E., 1999. Determination of uptake kinetics (sampling rates) by lipidcontaining semipermeable membrane devices (SPMDs) for polycyclic aromatic hydrocarbons (PAHs) in water. Environ. Sci. Technol. 33, 3918-3923.

Huckins, J.N., Petty, J.D., Prest, H.F., Orazio, C.E., Gale, R.W., 1997b. Important considerations in semipermeable membrane devices (SPMDs) design, application, performance and data comparability. 18th Annual Meeting of Society of Environmental Toxicology and Chemistry, 1620th of November, San Francisco CA, PTP055.

Huckins, J.N., Tubergen, M.W., Lebo, J.A., Gale, R.W., Schwarz, T.R., 1990a. Polymeric film dialysis in organic solvent media for cleanup of organic contaminants. J. Assoc. Off. Anal. Chem. 73, 290-293.
Huckins, J.N., Tubergen, M.W., Manuweera, G.K., 1990 b. Semipermeable membrane devices containing model lipid: a new approach to monitoring the bioavailability of lipophilic contaminants and estimating their bioconcentration potential. Chemosphere 20, 533-552.

Huckins, J.N., Petty, J.D., Lebo, J.A., Almeida, F.V., Booij, K., Alvarez, D.A., Cranor, W.L., Clark, R.C., Mogensen, B.B. Development of the permeability/performance reference compound approach for in situ calibration of semipermeable membrane devices. Environ. Sci. Technol., in press.

Johnson, G.D., 1991. Hexane-filled dialysis bags for monitoring organic contaminants in water. Environ. Sci. Technol. 25, 1897-1903.

Johnson, B.T., 1995. Collection and detection of petroleum products from air, water, and sediment: SPMDs and microbics toxicity test systems as a screening tool. Third Annual SPMD Workshop and Symposium. US Department of Interior, Columbia Environmental Research Center, Columbia, MO.

Johnson, B.T., Petty, J.D., Huckins, J.N., 2000. Collection and detection of lipophilic chemical contaminants in water, sediment, soil and air. Environ. Toxicol. 15, 248-252.

Koistinen, J., Lehtonen, M., Tukia, K., Soimasuo, M., Lahtipera, M., Oikari, A., 1998. Identification of lipophilic pollutants discharged from a finish pulp and paper mill. Chemosphere 37, 219-235.

Kukkonen, J.V.K., Rantalainen, A.-L., Mikkelson, P., Lyytikainen, M., Hamalainen, H., Passivirta, J., 1998. Bioavailability of polychlorinated diphenylethers (PDPEs) in contaminated sediments: comparison of benthic organisms and semipermeable membrane devices (SPMDs). Organohalogen Compounds 39, 5-8.

Lebo, J.A., Gale, R.W., Petty, J.D., Tillitt, D.E., Huckins, J.N., Meadows, J.C., Orazio, C.E., Echols, K.R., Schroeder, D.J., Inmon, L.E., 1995. Use of semipermeable membrane device as an in situ sampler of waterborne bioavailable PCDD and PCDF residues at sub-parts-perquadrillion concentrations. Environ. Sci. Technol. 29, 2886-2892.

Lebo, J.A., Zajicek, J.L., Huckins, J.N., Petty, J.D., Peterman, P.H., 1992. Use of semipermeable membrane devices for in situ monitoring of polycyclic aromatic hydrocarbons in aquatic environments. Chemosphere 25, 697-781.

Lohmann, B., Corrigan, B.P., Howsam, M., Jones, K.C., Ockenden, W.A., 2001. Further developments in the use of semipermeable membrane devices (SPMDs) as passive air samplers for persistent organic pollutants: field application in a spatial survey of PCDD/Fs and PAHs. Environ. Sci. Technol. 35, 2576-2582.

Macrae, J.D., Hall, K.J., 1998. Comparison of methods used to determine the availability of polycyclic aromatic hydrocarbons in marine sediment. Environ. Sci. Technol. 32, 3809-3815.

Meadows, J.C., Echols, K.R., Huckins, J.N., Borsuk, F.A., Carline, R.F., Tillitt, D.E., 1998. Estimation of uptake rate constants for PCB congeners accumulated by semiperme- 
able membrane devices and brown trout (salmo trutta). Environ. Sci. Technol. 32, 1847-1852.

Meadows, J.C., Tillitt, D.E., Huckins, J.N., Schroeder, D., 1993. Large-scale dialysis of sample lipids using a semipermeable membrane device. Chemosphere 26, 1993-2006.

Meadows, J.C., Tillitt, D.E., Schwartz, T.R., Schroeder, D.J., Echols, K.R., Gale, P.W., Bursian, S.J., 1996. Organochlorine contaminants in double-crested cormorants from Green Bay, Wisconsin: 1. Large-scale extraction and isolation from eggs using semi-permeable membrane dialysis. Arch. Environ. Toxicol. Chem. 31, 218-224.

Moring, J.B., Rose, D.R., 1997. Occurrence and concentrations of polycyclic aromatic hydrocarbons in semipermeable membrane devices and clams in three urban streams of the Dallas-Fort Worth metropolitan area, Texas. Chemosphere 34, 551-566.

Niewolny, L.A., Villeneuve, D.L., Devita, W.M., Crunkilton, R.L., Browne, B.A., 1995. Assessment of nonpolar contaminants in water conservation area-2A of the Florida everglades using semipermeable polymeric membrane devices. Third Annual SPMD Workshop and Symposium. US Department of Interior, Columbia Environmental Research Center, Columbia, MO.

Ockenden, W.A., Sweetman, A.J., Prest, H.F., Steinnes, E., Jones, K.C., 1998. Toward an understanding of the global atmospheric distribution of persistent organic pollutants: the use of semipermeable membrane devices as time-integrated passive samplers. Environ. Sci. Technol. 32, 2795 2803.

Orazio, C., Petty, J., Huckins, J., Clark, R., Lebo, J., Gibson, V., Kaiser, E., 1995. Laboratory calibration of SPMDs for sampling waterborne PAHs. Third Annual SPMD Workshop and Symposium. US Department of Interior, Columbia Environmental Research Center, Columbia, MO.

Parrott, J., Hodson, P., Tillitt, D., Bennie, D., Comba, M., 1995. SPMDs accumulate inducers of fish MFO from pulp mill and oil refinery effluents. Third Annual SPMD Workshop and Symposium. US Department of Interior, Columbia Environmental Research Center, Columbia, MO.

Pawliszyn, J., 1997. Solid Phase Microextraction: Theory and Practice. Wiley, New York.

Pekol, T.M., Cox, J.A., 1995. Preconcentration of organic compounds from water across dialysis membranes into micellar media. Environ. Sci. Technol. 29, 1-6.

Petty, J.D., Poulton, B.C., Charbonneau, C.S., Huckins, J.N., Jones, S.B., Cameron, J.T., Prest, H.F., 1998. Determination of bioavailable contaminants in the lower Missouri River following the flood of 1993. Environ. Sci. Technol. 32, 837-842.

Petty, J.D., Huckins, J.N., Orazio, C.E., Lebo, J.A., Clark, R.C., Gibson, V.L., 1994. Laboratory studies of the use of semipermeable membrane devices (SPMDs) as passive water samples of polyaromatic hydrocarbon (PAH) priority pollutants, Final report to the American Petroleum Institute on grant 93-045; National Biological Survey; Columbia, MO.
Petty, J.D., Huckins, J.N., Orazio, C.E., Lebo, J.A., Poulton, B.C., Gale, R.W., Charbonneau, C.S., Kaiser, E.M., 1995. Determination of bioavailable organochlorine pesticide residues in the lower Missouri River. Environ. Sci. Technol. 29, 2561-2566.

Petty, J.D., Orazio, C.E., Huckins, J.N., Gale, R.W., Lebo, J.A., Meadows, J.C., Echols, K.R., Cranor, W.I., 2000. Considerations involved with the use of semipermeable membrane devices for monitoring environmental contaminants. J. Chromatogr. 879, 83-95.

Peven, C.S., Uhler, A.D., Querzoli, F.J., 1996. Caged mussels and semipermeable membrane devices as indicators of organic contaminant uptake in Dorchester and Duxbury Bays, Massachusetts. Environ. Toxicol. Chem. 15, 144149.

Prest, H., Petty, J.D., Huckins, J.N., Gustafson, K.E., Dickhut, R.M., 1998. Validity of using semipermeable membrane devices for determining aqueous concentrations of freely dissolved PAHs. Environ. Toxicol. Chem. 17, 535536.

Prest, H.F., Jarman, W.M., Burns, S.A., Weismuller, T.M., Huckins, J.N., 1992. Passive water sampling via semipermeable membrane devices in concert with bivalves in the Sacramenta/San Joaquin River Delta. Chemosphere 25, 1811-1823.

Prest, H.F., Jacobson, L.A., Huckins, J.N., 1995a. Passive sampling of water and coastal air via semipermeable membrane devices. Chemosphere 30, 1351-1361.

Prest, H.F., Huckins, J.N., Petty, J.D., Herve, S., Paasivirta, J., Heinonen, P., 1995b. A survey of recent results in passive sampling of water and air by semipermeable membrane devices. Mar. Pollut. Bull. 31, 306-312.

Rantalainen, A.L., Ikonomou, M.G., Rogers, I.H., 1998. Lipid-containing semipermeable membrane devices (SPMDs) as concentrators of toxic chemicals in the lower Fraser River, Vancouver, British Columbia. Chemosphere 37, 1119-1138.

Rantalainen, A.L., Cretney, W., Ikonomou, M.G., 2000. Uptake rates of semipermeable membrane devices (SPMDs) for PCDDs, PCDFs, and PCBs in water and sediment. Chemosphere 40, 147-158.

Sabaliunas, D., Ellington, J., Sabaliuniente, I., 1999. Screening bioavailable hydrophobic toxicants in surface waters with semipermeable membrane devices: role of inherent oleic acid in toxicity evaluations. Ecotox. Environ. Saf. 44, $160-167$.

Sabaliunas, D., Lazutka, J., Sabaliuniene, I., Sodergren, A., 1998. Use of semipermeable membrane devices for studying effects of organic pollutants: comparison of pesticide uptake by semipermeable membrane device and mussels. Environ. Toxicol. Chem. 17, 1815-1824.

Sabaliunas, D., Sodergren, A., 1997. Use of semipermeable membrane devices to monitor pollutants in water and assess their effects: a laboratory test and field verification. Environ. Pollut. 96, 195-205.

Sodergren, A., 1987. Solvent-filled dialysis membranes simulate uptake of pollutants by aquatic organisms. Environ. Sci. Technol. 21, 855-863. 
Sodergren, A., 1990. Monitoring of persistent, lipophilic pollutants in water and sediment by solvent-filled dialysis membranes. Ecotoxicol. Environ. Saf. 19, 143-149.

Strandberg, B., 1998. PhD Thesis: the use of semipermeable membrane devices in studies of concentrations, distribution and fate of organochlorine compounds in the environment.

Stuer-Lauridsen, F., Kjolholt, J., 2000. Identification of selected hydrophobic organic contaminants in wastewater with semipermeable membrane devices (SPMDs). Water Res. 34, 3478-3482.

Utvik, T.I.R., Johnsen, S., 1999a. Bioavailability of polycyclic aromatic hydrocarbons in the North Sea. Environ. Sci. Technol. 33, 1963-1969.

Utvik, T.I.R., Durell, G.S., Johnsen, S., 1999b. Determining produced water originating polycyclic aromatic hydrocarbons in North Sea waters: comparison of sampling techniques. Mar. pollut. Bull. 38, 977-989.

Wang, Y., Wang, Z.J., Wang, C.X., Wang, W.H., 1999a. Uptake of weakly hydrophobic nitroaromatics from water by semipermeable membrane devices (SPMDs) and by goldfish (Carassius auratus). Chemosphere 38, 51-66.

Wang, Y., Wang, Z.J., Liu, J.A., Ma, M., Belzile, N., 1999b. Monitoring priority pollutants in the Yanghe River by dichloromethane extraction and semipermeable membrane device (SPMD). Chemosphere 39, 113-131.

Wang, Y., Wang, C.X., Wang, Z.J., 1998. Uptake of moderately hydrophobic chlorophenols from water by semipermeable membrane devices (SPMDs) and by goldfish (carassius auratus). Chemosphere 37, 327-329.

Wood, C.A., 1994. Comparison of chemical bioaccumulation by lipid-filled semipermeable membrane devices (SPMDs) and Caged channel catfish exposed to select lake Michigan tributaries. Second International Semipermeable Membrane Devices Workshop. US Department of the Interior, Columbia Environmental Research Center, Columbia, MO.

Zabik, J.M., 1988. Personal Communication. Pesticide Research Center and Department of Entomology, Michigan State University, East Lancing, MI.

Zabik, J.M., Aston, L.S., Seiber, J.N., 1992. Rapid characterization of pesticides in contaminated soils by passive sampling devices. Environ. Toxicol. Chem. 11, 765-770.

Zimmerman, L.R., Thurman, E.M., Bastian, K.C., 2000. Detection of persistent organic pollutants in the Mississippi Delta using semipermeable membrane devices. Sci. Total Environ. 248, 169-179. 